\title{
Teleologia, Darwinismo e Economia Evolucionária: a Controvérsia Acerca do Papel da Seleção Natural no Comportamento da Firma
}

\section{Teleology, Darwinism and Evolutionary Economics: the Controversy about the Role of Natural Selection in Firm's Behavior}

Manuel Ramon Souza Luz*
Paulo Sergio Fracalanza**

Resumo: Partindo de uma análise dos conceitos teóricos que fundamentaram as principais conquistas da biologia evolucionária moderna, este artigo pretende fornecer elementos para uma compreensão profícua acerca argumentos mobilizados em um momento específico da historia do pensamento econômico, dentro do que ficou conhecido como a controvérsia marginalista. Nesse sentido, a partir do referencial da biologia evolucionaria, o artigo centra-se na análise dos argumentos que remeteram a uma ideia de processo evolucionário, utilizado por diversos autores engajados no debate da controvérsia marginalista, explicitando dessa maneira como um ponto de vista estritamente Darwiniano pode jogar luz sobre os aspectos teóricos de abordagens econômicas muitas vezes rotuladas como evolucionárias.

Palavras-chave: Economia evolucionária. Controvérsia marginalista. Darwinismo. Seleção natural.

Abstract: Departing with an analysis of the theoretical concepts that founded the major achievements of modern evolutionary biology, this paper seeks to give elements for a fruitful understanding of the arguments deployed in a specific moment of the history of economic thought, in what became known as maginalist controversy. In this sense, based on the referential of evolutionary biology, this paper focuses on the analysis of the arguments that used an idea of evolutionary process expressed by several authors engaged in the debate

Doutorando do Instituto de Economia (IE) da Universidade Estadual de Campinas (Unicamp). Bolsista CNPq. E-mail: manuelramon06@gmail.com

* * Professor doutor do Instituto de Economia (IE) da Universidade Estadual de Campinas (Unicamp). Pesquisador do Núcleo de Economia Industrial e da Tecnologia. E-mail: fracalan@ eco.unicamp.br 
of marginalist controversy, showing that a strictly Darwinian point of view can shred light on the theoretical aspects of economical approaches often labeled as evolutionary.

Keywords: Evolutionary economics. Marginalist controversy. Darwinism. Natural selection.

JEL Classification: B2; B4; L1.

\section{Introdução}

O uso disseminado do termo economia evolucionária é uma característica marcante do presente estágio das ideias econômicas. Apesar das raízes dessa concepção estarem presentes nos desenvolvimentos do institucionalismo original de Thorstein Veblen e John Commons, as ideias evolucionárias que permeiam o pensamento econômico atual não são necessariamente associadas ao apelo vebleniano de construir uma ciência econômica fundada em um ideal "pós-darwiniano" (VEBLEN, 1898).

Se, num certo sentido, a difusão do termo economia evolucionária é uma característica típica do desenvolvimento atual das ciências econômicas, ${ }^{1}$ por outro lado, apesar desta evidente popularização, constata-se que o rótulo economia evolucionária é recorrentemente esvaziado de sentido, uma vez que o termo não carrega consigo uma concepção evolucionária claramente definida.

Entender o conceito de "economia evolucionária" como uma abordagem que compreende os processos de desenvolvimento como transformação estrutural é, segundo Hodgson (1998), usual nas ciências econômicas. Porém, tal definição, sendo extremamente geral, permite pouca, senão nenhuma possibilidade de demarcação clara entre quais concepções econômicas podem ser compreendidas como "evolucionárias" e quais não. ${ }^{2}$ Ademais, nos dias atuais, o uso do termo aparece

1 Witt (2008, p. 547-548) assinala o crescimento impressionante, a partir dos anos 1980, do uso do termo evolucionário e suas variações etimológicas na base de dados EconLit, chegando em 2005 a constar em $1 \%$ das palavras-chave dos journals desta base. Hodgson (2001, p. 25) apresenta um gráfico em que podemos observar a proliferação do uso do termo evolução nas publicações acadêmicas a partir da década de 1980 comparadas a seu uso menos disseminado em décadas anteriores. Hodgson associa a disseminação do termo à grande repercussão na academia do livro Uma Teoria Evolucionária da Mudança Econômica de Nelson e Winter (1982). Nesse sentido vale ressaltar que a popularização da vertente evolucionária gerou uma publicação específica dedicada ao tema, o Journal of Evolutionary Economics, que iniciou a seus trabalhos a partir de 1991.

2 Hodgson (1998) destaca que com essa definição ampla poderíamos classificar como "economistas evolucionários", boa parte dos grandes expoentes da história do pensamento econômico como Smith, Marx, Schumpeter, Veblen, Keynes etc. 
ainda com menos restrições do que a dada pela definição geral acima, uma vez que muitos economistas publicam trabalhos em que utilizam a palavra "evolucionário" como mero sinônimo de algum tipo de consideração dinâmica. (WITT, 2008; HODGSON, 2001).

Diferentemente do que ocorre na Economia, nas Ciências Biológicas não acontecem controvérsias sobre o estatuto e alcance da perspectiva evolucionária. Na Biologia produziu-se historicamente um robusto consenso científico, a partir do pioneirismo de Darwin (1859), acerca dos princípios e mecanismos que guiam os processos evolucionários. Tanto é assim que cremos que, se existe uma forma de pensamento evolucionário apropriado para compreender os processos de mudança em diferentes arenas, para além da biológica, esta reside não no plano das analogias, mas sim num nível mais profundo, como um componente ontológico darwiniano que permite uma explanação unificada dos processos mais gerais dos fenômenos evolucionários. ${ }^{3}$

Portanto, este trabalho parte desses dois argumentos: o primeiro, de que atualmente observa-se um fenômeno de disseminação terminológica associado a um recorrente esvaziamento de sentido da ideia de "economia evolucionária" e, o segundo, de que a abordagem darwiniana conforma um código de ciência que comporta os princípios fundamentais de uma perspectiva verdadeiramente evolucionária.

Nesse sentido, a proposta deste artigo é entender, a partir de uma concepção fundada nos princípios que guiam o pensamento evolucionário darwiniano, um momento específico da história das ideias econômicas, identificado aqui como um período-chave para a compreensão dos caminhos que a perspectiva evolucionária seguiu na Economia. Assim sendo, o artigo irá analisar de forma crítica a utilização do argumento da Seleção Natural, dentro de um importante debate ocorrido em meados do último século, conhecido pelo rótulo de controvérsia marginalista. Desta forma, partindo das concepções evolucionárias contidas no artigo de Alchian (1950), intitulado Uncertainty, Evolution and Economic Theory, procuraremos mostrar como esse trabalho abriu caminho para duas interpretações "evolucionárias" distintas, cristalizadas nos trabalhos de Friedman (1953) e Winter (1964).

Partindo da caracterização do processo de Seleção Natural e de sua relação com a hipótese de maximização de lucros apresentada por Alchian (1950), analisaremos quais foram os desenvolvimentos teóricos

Apesar de considerarmos a perspectiva darwiniana um sinônimo de abordagem evolucionária, o trabalho não debruçar-se-á sobre o atual debate acerca da adoção de uma ontologia darwiniana para compreender os processos econômicos. Para um melhor entendimento sobre este tema específico, recomendamos a leitura de Dawkins (1983), Hodgson (2002, 2007), Hodgson e Knudsen (2006), Cordes (2006), Possas (2008) e Luz e Fracalanza (2008). 
decorrentes de tal construção elaborados tanto pela abordagem neoclássica, representada por Friedman (1953), quanto pela visão neoschumpeteriana, de Winter (1964). De forma paralela, o artigo buscará pontuar os fundamentos que caracterizam a metodologia evolucionária darwiniana, permitindo assim dar elementos para analisar as relações entre as distintas visões de Seleção Natural e maximização dentro da controvérsia marginalista. Desta forma, buscaremos verificar a repercussão dos desenvolvimentos da biologia evolucionária sobre as ideias econômicas geradas neste debate específico e, ao mesmo tempo, analisar a consistência dessas ideias, a partir de um ponto de vista estritamente darwiniano.

Buscando alcançar estes objetivos, o artigo será composto por seis itens, além desta introdução. No segundo item, organiza-se uma breve revisão dos principais desenvolvimentos da biologia evolucionária construídos durante a primeira metade do século XX, destacando o que ficou conhecido como a "teoria sintética da Evolução", tida como o maior avanço do pensamento evolucionário ocorrido desde a publicação da Origem das Espécies (1859). Tal revisão histórica é essencial, pois trata exatamente da síntese final dos fundamentos do pensamento evolucionário moderno, pensamento este que influenciou fortemente a controvérsia marginalista através do trabalho de Alchian (1950) e as concepções de "economia evolucionária" desenvolvidas posteriormente. No terceiro item serão revisadas as ideias fundamentais do argumento de Seleção Natural e a ideia da firma maximizadora de Alchian (1950), assim como as decorrências teóricas desenvolvidas no trabalho de Enke (1951). No quarto item, apresenta-se o refinamento neoclássico destas ideias de fundo evolucionário, consubstanciado no trabalho de Friedman (1953). Neste aspecto, procuraremos evidenciar que Friedman (1953) altera a concepção de maximização de lucros do formato "animista" para uma hipótese "teleológica", no sentido da crítica vebleniana. Na sequência, no quinto item, elencam-se as principais críticas a esta concepção essencialista do argumento de Seleção Natural, evidenciando que esta abordagem não é compatível com os fundamentos teóricos das ciências evolucionárias modernas. No sexto item, analisa-se o conciso modelo evolucionário geral de Winter (1964), procurando evidenciar como esta construção pode ser legitimamente caracterizada como evolucionária, conquanto passível de ser compreendida a partir dos elementos metodológicos das categorias analíticas darwinianas. Finalmente, num sétimo e último item, organizam-se as considerações finais. 


\section{Os Desenvolvimentos Científicos da Biologia Evolucionária: a Teoria Sintética da Evolução}

O artigo de Alchian (1950) foi seminal para o debate acerca do argumento da Seleção Natural e a maximização de lucros da firma neoclássica. Os desenvolvimentos científicos daquele momento, principalmente no campo da biologia, foram extremamente propícios para a elaboração e a aceitação de sua analogia evolucionária.

Hodgson (1998) é claro em salientar que a ideia de Alchian (1950) era fruto de um momento de efervescência evolucionária nas ciências biológicas: "Capitalizing on the triumph of a new Darwinian biology, he made an explicit appeal to the metaphor of natural selection" (HODGSON, 1998, p. xxi).

Nesse sentido, é necessário compreender que, durante a primeira metade do século XX, as ciências biológicas estavam realizando um profundo processo de reorganização e sistematização, que redefiniu as bases metodológicas da abordagem darwiniana. As palavras de Simpson (1947) enfatizam a importância desse momento histórico para o pensamento evolucionário: "Cabe ao futuro julgar, mas parece provável que se fez ultimamente maior progresso real na compreensão dos processos evolutivos do que em todos os séculos precedentes de estudos somados" (SIMPSON, 1947, p. 53).

De forma breve, pode-se dizer que, do início do século XX até os anos 30, vigorou um verdadeiro dilema a respeito da teoria da evolução darwiniana. Os naturalistas (paleontólogos e morfólogos) não estavam suficientemente familiarizados com os avanços da genética dos primeiros pesquisadores mendelianos e, através de suas observações, entendiam que as mudanças na natureza se davam de forma gradual: "[...] são contínuas, graduais - em geral não se observam mudanças súbitas e pronunciadas - progressivas e orientadas, continuam na mesma direção durante longos períodos" (CARTER, 1953, p. 62). Os primeiros geneticistas, ao contrário de seus pares naturalistas e ignorando a rica literatura sobre variação geográfica e especiação, entendiam as mutações como rápidas e de grandes proporções, porém na maioria das vezes degenerativas, resultando mais em perdas do que na elaboração de estruturas. Mayr (2006) assinala a disparidade entre as abordagens destes grupos:

Os dois grupos lidavam com níveis hierárquicos diferentes: os geneticistas com a variação intrapopulacional ao nível gênico, os naturalistas com a variação geográfica das populações e das espécies. Quando geneticistas e paleontólogos, ou, geneticistas e taxonomistas se reuniam naquela época, as 
suas respectivas experiências eram tão diferentes que eles, aparentemente, eram incapazes de se comunicar uns com os outros. (MAYR, 2006, p. 133).

Assim sendo, ficou patente que faltava um fundamento lógico à teoria de Darwin que unisse estas perspectivas díspares e, de alguma forma, nesse momento, começava-se até mesmo a duvidar de que a teoria darwiniana tivesse validade geral (JABLONKA; LAMB, 2005, p. 21). A problemática girava em torno de duas questões centrais da teoria da Evolução: a primeira, era que não havia evidências diretas de que a Seleção Natural operava na natureza; a segunda, era que havia pouca compreensão a respeito de como as leis da variabilidade e hereditariedade atuavam. Gould (1982) aponta para o antagonismo das diferentes abordagens decorrentes deste momento específico:

Battles of the late nineteenth century had pitted two primary contenders against each other: 1) Darwinian natural selection, with its insistence upon random variation as raw material and selection as creative force; and 20 a host of otherwise disparate alternatives, including neo-Lamarckism and various styles of orthogenesis and vitalism, that proposed a creative role for variation itself and relegated natural selection to an executioner's task as eliminator of the unfit. (GOULD, 1982, p. xviii).

Foi objetivando resolver estes pontos de conflito sobre a teoria darwiniana que, entre a década de 1930 e 1950, ocorre o que ficou conhecido como a segunda Revolução Darwiniana, a qual fundou as bases do desenvolvimento das ciências biológicas nos termos conhecidos atualmente. Desta forma, durante os anos 30, começou a ser construído o que conhecemos como a síntese moderna da biologia evolucionária ou simplesmente teoria sintética da Evolução. Tal desenvolvimento foi resultado de um esforço conjunto de especialistas de diferentes ramos das ciências biológicas, centralizado principalmente nos EUA.

Impelidos pela necessidade de coordenação e síntese, estes pesquisadores buscaram compreender as inter-relações dos diferentes aspectos da evolução. A superação das barreiras entre as especialidades dentro das ciências biológicas e a sua integração dentro de um arcabouço explicativo geral foi a característica fundamental deste processo aglutinador. ${ }^{4}$ Assim sendo, foram criados diversos órgãos de pesquisa, principalmente nos EUA, que levaram a frente tais estudos:

4 Segundo Gould (1982), podemos relacionar os seguintes pesquisadores, autores-chave deste processo, às suas respectivas áreas de atuação: Dobzhansky (genética), Mayr (sistemática), Simpson (paleontologia), Rensch (morfologia) e Stebbins (botânica). 
Nos EUA, ele foi empreendido pela Comissão sobre Problemas Comuns de Genética, Paleontologia e Sistemática do Conselho Nacional de Pesquisa. Os trabalhos das comissões foram ampliados e colocados em base permanente com a fundação de uma Sociedade para o Estudo da Evolução (em 1946). (SIMPSON, 1947, p. 52).

Segundo Mayr (2006), a síntese não foi propriamente uma revolução científica, mas foi uma unificação de campos de estudos evolucionários sob uma linguagem comum. Tal unificação foi caracterizada "nem tanto por novos conceitos revolucionários, mas mais por um processo de saneamento e pela total rejeição de várias teorias errôneas e crenças que haviam sido responsáveis por divergências anteriores" (MAYR, 2006, p. 135).

A ideia central desta síntese científica girava fundamentalmente numa combinação entre as contribuições dos trabalhos de Weismann e Mendel: 5 "Weismann's ultra-Darwinism was combined with Mendelian genetics, which had adopted the concept of gene as the hereditary unit of biological information" (JABLONKA; LAMB, 2005, p. 24). Hodgson (1998) assinala, neste mesmo sentido, a contribuição teórica fundamental proveniente deste processo de síntese que revolucionou as ciências evolucionárias:

Only then did the Mendelian gene became fully incorporated into the theory of evolution, giving a plausible explanation of the presumed variation of offspring and the selection of species. This had not been achieved by Darwin or any other nineteenth-century biologist. (HODGSON, 1998, p.xxi).

Através da ideia de que existe um processo de mudança evolucionária gradual, em que pequenas diferenciações, ou diferenciações maiores, nos cromossomos e, por consequência, nos indivíduos são

5 A contribuição fundamental de Weismann foi o descarte completo da ideia de herança de características adquiridas. Para Weismann uma mudança induzida pelo ambiente no indivíduo não seria repassada para as gerações seguintes, a não ser que esta mudança alterasse a "linha de germe", ou seja, os gametas dos indivíduos. Por outro lado, Mendel produzira uma teoria sobre a hereditariedade totalmente nova. Para Mendel os indivíduos possuem unidades hereditárias (genes) que estão dispostas em pares (alelos). Os pares são divididos e recombinados no momento da reprodução sexual. A primeira lei de Mendel diz que durante a formação dos gametas os alelos se separam, abandonando o indivíduo da mesma forma que entraram, sem nenhuma alteração decorrente do tempo em que permaneceram no corpo. A segunda lei de Mendel defende que os alelos se separam de forma independente, proporcionando uma grande quantidade de variações entre os alelos que formam os gametas. Outra importante descoberta de Mendel foi a concepção de dominância e recessividade entre os alelos, excluindo a ideia de que a prole apresentaria características intermediárias de seus progenitores (Jablonka; Lamb, 2005). Ainda sobre a introdução da genética como o mecanismo da evolução, não podemos deixar de citar a importância do trabalho seminal de Theodosius Dobzhansky para esta síntese, Genetics and the Origin of Species, de 1937. 
sujeitas à seleção, conciliou-se a perspectiva genética com a teoria da evolução darwiniana. De forma concisa, podem-se explicitar os conceitos dessa abordagem sintética através dos seguintes pontos: i) a herança se dá através da transmissão de genes, as unidades dos cromossomos. Os genes possuem informação sobre as características dos indivíduos e são o substrato físico da hereditariedade; ii) a variação (mutação) é derivada de mudanças acidentais nos genes decorrentes da falta de precisão na propriedade básica de autorreprodução; ${ }^{6}$ iii) a seleção ocorre sobre os indivíduos e depende da interação entre os ambientes e os fenótipos desses indivíduos. ${ }^{7}$

O gene, como fica evidenciado nos pontos explicitados acima, é o elemento principal que governa o processo de mudança na teoria sintética da Evolução. Huxley (1954) é claro em mostrar a "supremacia" do gene como unidade de análise evolucionária:

Um único mecanismo básico fundamenta toda a evolução orgânica: a seleção darwiniana agindo sobre o mecanismo genético. A seleção darwiniana é um princípio estabelecido, mas atua conforme a natureza do mecanismo genético. (HUXLEY, 1954, p. 22).

Durante as décadas de 1940 e 1950, devido aos avanços da bioquímica, a teoria sintética da Evolução foi complementada pelas descobertas da biologia molecular. A constatação de que o ácido desoxirribonucleico (DNA) era a única substância hereditária nos processos biológicos e que havia um fluxo unidirecional de informação do DNA para as proteínas, mudou a forma de o homem pensar o gene. O DNA passou a ser reconhecido como regulador das atividades do gene e não apenas um codificador de proteínas, a relação entre genótipo e fenótipo passou a ser a relação entre plano e produto. ${ }^{8}$

6 Este ponto refuta a ideia lamarckista de variação envolvendo a herança de características adquiridas. Desta forma é importante ressaltar que apenas a partir da teoria sintética da Evolução que o lamarckismo foi totalmente abandonado como teoria. O mesmo não ocorre quando compreendemos a concepção de evolução do próprio Darwin. Hodgson (2004; 2007), Simpson (1947) e Dawkins (1983), tratam da diferença das abordagens de Darwin e da síntese moderna da biologia evolucionária.

7 Esta questão foi intensamente debatida nas obras de Stephen Jay Gould e Richard Dawkins, já que para o último os indivíduos são governados por genes e, portanto, são os próprios genes, e não os indivíduos, em última instância, que estão sujeitos à seleção. Gould já defende a ideia de que existem diferentes níveis de seleção e as unidades podem variar. Estas podem ser os indivíduos, os grupos ou as espécies.

8 É importante ressaltar que nos dias atuais tal distinção entre plano e produto é controversa. A microbiologia moderna levanta a possibilidade de que exista também uma relação inversa, a repercussão do ambiente no produto e este afetando o plano: "No longer can we think about mutation solely in terms of random failures in DNA maintenance and repair. We know now that stress conditions can affect the operation of the enzyme systems that are responsible for 
A síntese moderna da biologia evolucionária lançou o entendimento acerca da evolução a um novo patamar analítico. Os estudos genéticos ocuparam as difíceis "lacunas" teóricas da evolução da concepção de Darwin (1859), explicando de forma consistente como se davam os processos de herança e mutação. Dobzhansky (1937) é claro em apresentar o caráter complementar da perspectiva genética na teoria da Evolução de Darwin:

Evolution is a process resulting in the development of dissimilarities between ancestral and descendant populations. The mechanisms that determine the similarities and offspring constitute the subject matter of genetics. (DOBZHANSKY, 1937, p. 9)

É paralelo a este contexto, de construção das teses centrais que guiaram a partir de então o pensamento das ciências biológicas, que a ideia acerca da Seleção Natural aplicada à hipótese de maximização de lucros da firma surgiu e foi desenvolvida. Como veremos, as repercussões dos avanços da biologia evolucionária apareceram de forma variada no debate econômico deste período. Nesse sentido, podemos dizer que a controvérsia marginalista apresentou diversos argumentos evolucionários, muitas vezes apenas como efeito retórico, abstendo-se de uma abordagem verdadeiramente inspirada numa perspectiva darwiniana.

\section{O Argumento da Seleção Natural e a Maximização}

Entre as décadas de 1940 e 1960, a sistematização alcançada pela economia neoclássica acerca da natureza e dos objetivos da firma fez emergir um profícuo debate sobre a validade dos fundamentos metodológicos dessa abordagem. A ampla discussão sobre o estatuto científico e os preceitos metodológicos da teoria da firma ficou conhecida como a controvérsia marginalista, ${ }^{9}$ a qual ecoou nas interpretações surgidas na década de 50 no âmbito da teoria da firma fundamentalmente nos

maintaining and repairing DNA, and parts of these systems sometimes seem to be coupled with regulatory elements that control, how, how much, and where DNA is altered" (JABLONKA; LAMB, 2005, p. 89).

9 A controvérsia marginalista envolveu a discussão sobre os princípios metodológicos da abordagem marginalista (neoclássica) do comportamento da firma em uma série de artigospublicados na American Economic Review entre 1947 e 1953. Contudo, num sentido menos estrito e que convenientemente adotamos aqui, a controvérsia marginalista refere-se às discussões sobre a teoria da firma que tiveram lugar em vários periódicos e conferências britânicas e norte-americanas entre 1939, com a publicação do célebre artigo de Hall e Hitch (1955). A esse respeito, ver especialmente Mongin. (1997). 
trabalhos de Baumol, Cyert e March e Marris (SCREPANTI; ZAMAGNI, 1997, p. 387; MONGIN, p. 1997).

O trabalho de Alchian (1950), Uncertainty, Evolution, and Economic Theory foi um dos trabalhos seminais nesta discussão. Sua contribuição, largamente influenciada pelos desenvolvimentos da biologia evolucionária vistos no tópico anterior, foi extremamente influente nas abordagens subsequentes, tanto na sua vertente neoclássica quanto em vertentes mais heterodoxas.

O "argumento da Seleção Natural", conhecido também como "hipótese da viabilidade", foi uma analogia biológica utilizada por Alchian (1950) e complementada por Enke (1951), para caracterizar o processo de competição capitalista entre as firmas. Através desta construção, Alchian (1950) buscou reformular as concepções acerca do comportamento da firma, afastando-se, de alguma forma, da abordagem fundada na maximização de lucros da teoria ortodoxa.

Alchian (1950) defende que a hipótese de maximização de lucros não é estritamente necessária como ferramenta explicativa dentro da teoria econômica. Segundo o autor, os agentes operam num mundo caracterizado pela incerteza, onde a maximização de lucros não é um guia de ação factível. A imprevisibilidade dos fenômenos econômicos, conjuntamente com a inabilidade humana de trabalhar com um grande número de variáveis, compromete a concepção de firmas como entidades maximizadoras. Assim sendo, Alchian (1950) restringe a hipótese de maximização apenas a uma ideia de mundo onde não exista incerteza: "The only way to make profit maximization a specifically meaningful action is to postulate a model containing certainty" (ALCHIAN, 1950, p. 255).

Nesse sentido, Enke (1951) também focou na incerteza para defender que a hipótese de maximização de lucros, no curto prazo, é inaceitável:

The explanation of this unreasonableness is not simple ignorance of the logic of profit-maximizing theories or the practical impossibility of knowing all the relevant functions of the moment and relating them to another. It is also that, in the face of future uncertainty, the profit-maximizing motive does not provide the entrepreneur with a single and unequivocal criterion for selecting one policy from among the alternatives open to him. (ENKE, 1951, p. 567).

A crítica de Alchian (1950) e Enke (1951) à hipótese de maximização, como bem observado por Hodgson (1998), encontra paralelo na crítica aos fundamentos da economia neoclássica levantados na obra de Thorstein Veblen. Nesse sentido, vale lembrar que a ideia de que a economia neoclássica imputa às firmas e aos indivíduos a lógica do "cálculo hedonista", determinado sob um formato "animista" é a base 
da crítica vebleniana. ${ }^{10}$ Alchian (1950), apesar de não dar créditos a Veblen, retoma a crítica deste autor e propõe como alternativa a retirada deste "animismo" com as vestes da maximização dos fundamentos do comportamento da firma. Por sua vez, Enke (1951) argumenta que apesar da firma se comportar com a intenção maximizar lucros, considerar que ela realmente os maximiza é uma coisa completamente diferente: "It is impossible for each isolated firm to maximize profits... The fundamental difficulty is that a desire to maximize profits does not provide the entrepreneur with an action prescription" (ENKE, 1951, p. 568).

É partindo dessa crítica à ideia de maximização neoclássica que o argumento da Seleção Natural de Alchian (1950) é construído. Tal ideia assenta-se sobre a concepção de que as firmas buscam uma solução satisfatória ou lucros positivos, mas não necessariamente lucros máximos. $\mathrm{O}$ autor substitui, nesse aspecto, a rigidez da pré-concepção do comportamento maximizador neoclássico por uma resultante de um processo de competição determinado pela busca de lucros. O sucesso, ou a viabilidade, das firmas depende dessa forma de sua sobrevivência num sistema econômico em que:

Realized positive profits, not maximum profits, are the mark of success and viability. It does not matter through what process of reasoning or motivation such success are achieved. The fact of its accomplishment is sufficient. This is the criterion by which the economic system selects survivors: those who realize positive profits are the survivors; those who suffer losses disappear. (ALCHIAN, 1950, p. 255).

Assim sendo, Alchian (1950) aponta para as diferenças de lucros entre as firmas como critério geral de um processo de seleção de mercado onde somente as empresas lucrativas prosperam. É importante compreender nesse sentido que para Alchian (1950) a competição levaria a resultados bons, mas não necessariamente aos melhores (ANDERSON, 1988).

Dessa forma, Alchian (1950) retira de sua abordagem o fundamento de maximização defendido pela teoria neoclássica, substituindo-o pelo argumento da Seleção Natural em que: "The crucial element is one's aggregate position relative to actual competitors, not some hypothetical perfect competitors" (ALCHIAN, 1950, p. 213).

Hodgson (1994) destaca a importância desta abordagem pioneira

10 Veblen (1900) utiliza o termo animismo para caracterizar um dos dois cânones de verdade dentro da economia neoclássica: imputar às unidades de análise (indivíduos e firmas) uma concepção psicológica hedonística-associativa. O outro cânone de verdade seria a convicção de tendência teleológica equilibrista, decorrente da interação destas "unidades hedonistas". 
de Alchian (1950): "Alchian sees the idea of evolutionary selection less as a buttress and more as an alternative to the assumption that individual firms are attempting to maximize their profits" (HODGSON, 1994, p. 415).

Buscando evitar compreensões equivocadas a respeito de sua metáfora biológica, entendida nos termos da teoria sintética da Evolução, Alchian (1950) é enfático em dizer que a sua abordagem, que utiliza explicitamente o termo "Seleção Natural", não considera que a mutação dentro do processo evolucionário "econômico" é construída de forma randômica, semelhante à variação aleatória dos genes da síntese moderna da biologia evolucionária. Alchian (1950) destaca que é evidente que a firma possui elementos de previsão e motivação que produzem um comportamento deliberado, completamente diferente, portanto, da forma como a variação aparece no mundo biológico.

Porém, apesar de reconhecer a especificidade da variação intencional no comportamento da firma, Alchian (1950) destaca que mesmo se não se levasse em consideração o comportamento deliberado das firmas e se fosse presumido, equivocadamente, que a alteração no comportamento das mesmas pudesse se dar de forma aleatória - como ocorre no construto da teoria sintética da Evolução - observar-se-ia que dentro do conjunto amplo das ações individuais haveria certamente comportamentos que seriam os "melhores" no sentido da adaptação às condições vigentes. Desta forma, o autor defende que mesmo se as firmas agissem sem um propósito definido, a Seleção Natural selecionaria aquelas empresas que obtivessem lucros positivos. Hirshleifer (1977), em comentário a esta visão, complementa: "[...] the environment would nevertheless select ("adopt") relatively correct decisions in the sense of meeting the positive realized profit condition of survival" (HIRSHLEIFER, 1977, p. 9).

A proposta de Alchian (1950) para entender o comportamento das firmas é compreendê-las como seguidoras de um leque regras que comandam suas ações e que apresentam como limite superior e inferior à ideia de comportamento aleatório e seu oposto, a hipótese maximizadora. Assim, Alchian (1950) traça dois tipos comportamentos que as firmas seguem: o comportamento imitativo e o comportamento baseado em tentativa e erro.

A explicação acerca do comportamento baseado em tentativa e erro chega a uma conclusão surpreendente, que abre um precedente teórico para uma nova concepção econômica acerca da hipótese de maximização da firma:"This has been used with 'profit maximization', wherein, by trial an ensuing success or failure, more appropriate actions are selected in process presumed to converge to a limit of "profit maximization' equilibrium" (ALCHIAN, 1950, p. 261). 
A regra de ação baseada na tentativa e erro gera elementos para uma perspectiva controversa na ideia de Seleção Natural na Teoria da Firma: no "limite" as firmas selecionadas tenderão a ser aquelas que maximizam. ${ }^{11}$ Enke (1951) concorda com essa ideia e a desenvolve. Este autor argumenta que as forças que fazem a competição se ajustar no longo prazo acabam selecionando as firmas que alcançam lucros máximos, sendo que tal resultado ocorreria como uma decorrência lógica do processo de competição capitalista. Neste sentido, Hirshleifer (1977) sintetiza a visão de Enke:

As firms pursuing successful policies expand and multiply, absorbing a larger fraction of the market, a higher and higher standard of behavior becomes the minimum criterion for competitive survival. In the long run, viability dictates optimality. (HIRSHLEIFER, 1977, p. 10).

Porém, Enke (1951) pondera que o longo prazo, que ditaria a proeminência de comportamentos ótimos, não é algo temporalmente alcançável:

Unfortunately, as is well known, long run equilibrium is in practice never attained. The processes of long-run adjustment are always being interrupted, before they work has been completed, by some new autonomous event. (ENKE, 1951, p. 571).

Apesar disso, Enke (1951) assinala, no mesmo sentido de Alchian (1950), que o economista, conhecedor das tendências de longo prazo, poderia prever como as firmas se ajustariam com o passar do tempo. Se, no longo prazo, em condições de concorrência perfeita, os participantes do mercado obtêm apenas lucros normais, não haveria espaço para comportamentos subótimos, ou seja, somente sobreviveriam as firmas que adotassem regras maximizadoras de lucros. Nesse sentido, Enke (1951), opinando sobre a teoria da concorrência monopolista de Chamberlin

11 É decorrente deste precedente teórico aberto por Alchian (1950) que temos hoje dois tipos de interpretações completamente distintas sobre a essência de seu trabalho. A ideia de que a perspectiva de Alchian (1950) introduziu uma concepção seletiva evolucionária alternativa à hipótese de maximização de lucros, como defendida por Hodgson (1994), não é consenso. Blume e Easley (2007) assinalam exatamente o contrário, defendendo que Alchian utilizou o argumento evolucionário para fundamentar a hipótese de maximização de lucros, sendo que esta é a verdadeira essência de seu trabalho: "It could be that market selects for firms and investors who behave "as if" they are rational. This last defence of the use of rationality is the essence of the quote from Alchian (1950)." (BLUME; EASLEY, 2007, p. 2). Na sequência do artigo, iremos ver que Friedman (1953) tem a mesma interpretação que Blume e Easley sobre a obra de Alchian. 
(1933), assinala a tendência de que somente as firmas com lucro máximo sobrevivem:

Professor Chamberlin's use of marginal analysis in his theory of 'monopolistic competition' is acceptable as an approximation; surviving firms compete sufficiently that long run profits must be meager, and when profits are meager there is little latitude for suboptimum policies. (ENKE, 1951, p. 577).

Uma decorrência da ideia de Alchian (1950) e Enke (1951) é a abordagem realizada por Friedman (1953), que refunda a hipótese da maximização de lucros baseada nos termos "evolucionários" explicitados acima. Na sequência buscaremos compreender os pontos fundamentais da intervenção de Friedman (1953), a qual foi especialmente influente como argumento de defesa da concepção de maximização neoclássica dentro da controvérsia marginalista.

\section{A Evolução Teleológica de Friedman}

O economista norte-americano Milton Friedman teve papel de destaque na controvérsia marginalista com um dos representantes da reação neoclássica neste debate. ${ }^{12}$

Em seu trabalho de 1953, The Methodology of Positive Economics, Friedman (1953) apresenta uma nova abordagem acerca da maximização. Tal concepção, assentada nas valiosas observações de Alchian (1950) e Enke (1951), reafirma os fundamentos da teoria da firma neoclássica em termos inovadores. Segundo Hodgson (1998), Friedman (1953) apropriou-se de certos conceitos evolucionários para justificar as hipóteses neoclássicas:

Friedman's use of metaphor of natural selection bolstered a key element in the mechanistic paradigm [...] Friedman has applied simplistically a half-assimilated idea from Darwinian biology to reinforce the mechanistic paradigm of neoclassical economics. (HODGSON, 1998, p. xxii).

A ideia de Seleção Natural como justificativa da maximização de lucros é claramente o resultado lógico dos elementos apresentados na aborda-

12 Machlup (1946) é um dos mais influentes autores na controvérsia marginalista e conjuntamente com Friedman promoveu a defesa da teoria neoclássica da firma, acusada de falta de realismo. Nos limites deste artigo, porém, recorreremos tão somente à contribuição de Friedman de 1953, uma vez que esse autor utiliza expressamente em seu trabalho o argumento da Seleção Natural. Para uma interessante discussão sobre a reação ortodoxa empreendida por Machlup e Friedman, ver Nelson e Winter (1982, edição brasileira de 2005, p. 142-149). 
gem de Alchian (1950) e Enke (1951). Como vimos no tópico anterior, esses dois autores já haviam levantado a hipótese de que um processo de seleção guiado pelos lucros positivos, no longo prazo ou no limite, selecionaria as firmas que maximizassem lucros.

Friedman (1953) constrói uma linha argumentativa que reforça a concepção de maximização, porém não reduzindo-a a uma tendência evolutiva de um processo temporalmente longo, mas sim como uma justificativa lógica, que a reafirma como elemento metodológico para analisar o presente. Desta maneira, Friedman (1953) transforma a maximização de lucro, de um resultado ex-post de um processo dito "evolucionário", para pressuposto ex-ante metodologicamente válido para explicar o comportamento da firma.

Buscando rebater as críticas à hipótese de maximização da teoria da firma neoclássica, Friedman (1953) salienta que qualquer argumento que seja construído apontando para os eventos que ocorrem dentro da firma como evidência de que estas não possuem capacidade de maximizar não afeta a visão de maximização de lucros como fundamento básico da teoria da firma ortodoxa. ${ }^{13}$ Friedman (1953) justifica a sua posição assinalando que a teoria da firma não deve ser compreendida como o que o próprio nome sugere - uma teoria sobre a firma - mas sim deve ser vista como uma teoria do comportamento de mercado, externo à firma.

Adotando essa posição, Friedman (1953) abstém-se de discutir os determinantes comportamentais que emergem da organização interna da firma, pois, segundo o autor, o realismo da teoria desenvolvida não é o ponto que realmente importa, mas sim o seu poder de previsão:

The relevant question to ask about the "assumptions" of a theory is not whether they are descriptively "realistic", for they never are, but whether they are sufficiently good approximations for the purpose in hand. And this question can be answered only by seeing whether the theory works, which means whether it yields sufficiently accurate predictions. (FRIEDMAN, 1953, p. 15)

Dessa forma, Friedman (1953) assinala que a hipótese de maximização permite previsões que são boas o suficiente para representar o comportamento das empresas em um mercado competitivo. Assim sendo, o autor é enfático em dizer que apesar dos homens de negócios não resolverem de forma literal um sistema de equações simultâneas, as

13 É interessante observar que neste ponto Friedman (1953) literalmente "seleciona" algumas críticas de Veblen à concepção "animista" da firma neoclássica. No próximo item do artigo, apresentaremos os questionamentos de Veblen que não foram analisados por Friedman. 
empresas comportam-se como se tivessem curvas disponíveis e marginalmente maximizassem os lucros. ${ }^{14}$

Para justificar a hipótese de maximização como resultante da ação da firma, Friedman (1953) retoma o argumento da Seleção Natural levantado por Enke (1951):

Whenever this determinant happens to lead to behavior consistent with rational and informed maximization of returns, the business will prosper and acquire resources with which to expand; whenever it does not, the business will tend to lose resources and can be kept in existence only by the addiction of resources from the outside. (FRIEDMAN, 1953, p. 22).

Dessa forma, Friedman (1953) faz duas afirmações que se reforçam mutuamente: a primeira é a ideia de que o importante é o poder de preditivo de uma teoria e não se ela representa a realidade de forma fiel. A segunda ideia é a de que existe um processo de Seleção Natural atuando sobre as firmas, permitindo que apenas as que maximizem os lucros persistam. Assim sendo, a Seleção Natural aparece como um reforço importante da hipótese de maximização, que surge como um resultado lógico de um processo competitivo. Com efeito, adotando a visão metodológica do como se, Friedman (1953) abandona a interpretação da maximização como uma característica inata da firma (animista) e entende que ela é resultado de um processo evolucionário com um fim teleológico, ou seja, pré-concebido. Essa tentativa de combinar o princípio de maximização, como teleologia, com argumentos evolucionários será alvo de uma das críticas fundamentais à hipótese de Seleção Natural de Friedman (1953), objeto do tópico a seguir.

\section{Maximização Evolucionária? Um Compêndio de Críticas}

Penrose (1952) critica asperamente o argumento de Seleção Natural de Alchian (1950). Para a autora, há grandes falhas na interpretação dos processos econômicos quando se utilizam "analogias biológicas". ${ }^{15} \mathrm{De}$

14 Screpanti e Zamagni (1997) enfatizam a famosa analogia de Friedman (1953) acerca da ideia do poder de previsão das hipóteses e o comportamento maximizador: "En esencia, para Friedman el empresario se comportaria como un experto jugador de billar que golpea la bola con la velocidad y el ángulo necesarios aun sin conocer las leyes de la física o de la geometria" (SCREPANTI; ZAMAGNI, 1997, p. 394-395). Winter (1971) destaca a importância desta construção teórica de Friedman como argumento de defesa na economia neoclássica: "Perfect information and costless computation assumptions are typical, for congent reasons of analytical tractability and empirical content. When this assumptions are challenged, the "as if" argument is invoked in defense" (WINTER, 1971, p. 243).

15 A autora realiza algumas críticas de caráter geral acerca do uso de analogias biológicas na economia. Devido a um problema de espaço e adequação, o presente artigo não irá versar 
forma enfática, Penrose (1952) assinala que a hipótese da viabilidade exclui o componente motivacional e intencional humano do próprio resultado das relações econômicas que, como visto no item anterior, é um desdobramento lógico desta particular concepção de Seleção Natural:

Individual motivation and foresight, while sufficient, are not necessary... Again we find that the characteristic of the analogy employed is to provide an explanation of human affairs that does not depend on human motives. (PENROSE, 1952, p. 810-812).

A crítica de Penrose (1952) é importante no sentido de chamar a atenção e trazer o homem de volta ao papel de protagonista dos processos econômicos. O ambiente, na visão de Alchian (1950), Enke (1951) e Friedman (1953), é uma entidade seletiva onipotente e externa aos elementos que o integram. Convém reiterar que nesta concepção mesmo que os agentes sigam um comportamento aleatório, o processo seletivo, no longo prazo, premiará os comportamentos maximizadores. Penrose acertadamente alerta que o próprio ambiente seletivo pode ser moldado e comandado pelas próprias entidades, sendo que estas não são apenas os objetos de um processo de seleção, mas também os agentes desse processo.

Hodgson (1994) e Winter (1964) assumem posição semelhante à de Penrose (1952) em relação à concepção de seleção. Winter é claro em estabelecer a interdependência entre ambiente e firma, compreendendo a dinâmica que este processo apresenta:

If the habitual reactions of some firms at a particular time are consistent with profit maximization, and if as a consequence these firms expand relative to other firms in the economy, this very fact will tend to alter the market price environment facing all firms. It is not clear why, in this altered environment, the same firms should continue to have good fortune to be closer to maximizing behavior than their competitors... the environment is changed by the dynamic process itself. (HODGSON apud WINTER, 1994, p. 448).

É importante assinalar que esta concepção ambiental interativa, ao contrário da visão "evolucionária" neoclássica apresentada, está totalmente de acordo com a abordagem darwiniana, sendo que esta perspectiva é reforçada pelos desenvolvimentos da "teoria sintética da

sobre esta questão. Para uma discussão mais aprofundada e atualizada acerca do uso de analogias biológicas, aconselham-se a leitura de Penrose (1952; 1959), Corazza e Fracalanza (2002), Hodgson (2002) e Possas (2008). Sobre o uso de metáforas e analogias na economia, sugere-se a leitura de McCloskey (1985), Klamer e Leonard (1994) e Leatherdale (1974). 
Evolução". Hodgson (1994) relembra Lewotin (1974) que argumenta que se as adaptações favoráveis podem ajudar as unidades envolvidas, o acúmulo destas adaptações pode produzir alterações no próprio ambiente. Assim, pode-se produzir uma situação em que a própria adaptação não permita mais resultados benéficos para as unidades (HODGSON, 1994, p. 449). Em artigo de 1956, o geneticista Theodosius Dobzhansky e o estatístico Gordon Allen, explicam a dinâmica do ambiente e a seleção na concepção da biologia moderna enfatizando a constante mutabilidade das condições ambientais:

A seleção evidencia a adaptabilidade dos genótipos apenas a ambientes existentes no momento. Por esse motivo, a direção e a intensidade da seleção natural são tão mutáveis quanto os ambientes. (DOBZHANSKY; ALLEN, 1956, p. 328).

Winter (1964) assinala que a justificativa para a hipótese de maximização adotada por Friedman (1953) não possui aplicabilidade geral para compreender o comportamento da firma. Winter defende que, para que exista um processo de seleção que leve somente a sobrevivência às firmas maximizadoras, seria necessário um modelo de mundo muito específico, determinado por um grande número de condições restritivas. De forma sintética, apresentamos a seguir estas imprescindíveis exigências teóricas explicitadas no artigo de Winter, para que a maximização ocorra. As condições seriam: i) a existência de um ambiente com informação perfeita e sem custo; ii) as firmas deveriam possuir funções de produção dadas, podendo fazer ajustamentos de curto prazo observando as condições de mercado; iii) as empresas comportar-se-iam de maneira competitiva (não podendo haver guerra de preços); iv) para cada empresa, haveria um limite cumulativo de perdas que quando atingido levaria à sua extinção; v) os retornos de escala teriam de ser constantes; ${ }^{16}$ vi) as empresas produziriam produtos idênticos com as mesmas condições de custo; vii) o lucro diferencial necessariamente levaria a maiores taxas de crescimento das maximizadoras em relação às não maximizadoras (os lucros não seriam, portanto, gastos no pagamento de dividendos ou em outros gastos que não implicassem crescimento); viii) a escala de produção das firmas tomadas em conjunto não poderia ser alta o suficiente para que os preços de mercado não permanecessem baixos por um período longo - pois a falta de lucros poderia fazer com que as firmas maximizadoras que não possuíssem recursos suficientes para sofrer recorrentes prejuízos

16 Hodgson (1994) discorda da condição de retornos constantes de escala de Winter (1964). Para Hodgson a condição restritiva deveria ser a de retornos decrescentes de escala com perturbações aleatórias. 
fossem extintas, enquanto que as não maximizadoras, que possuíssem maiores recursos, permanecessem no mercado. ${ }^{17}$

Explicitando este rol de condicionantes, Winter (1964) restringe a aplicabilidade da abordagem de Friedman (1953), evidenciando que a ideia de processo de Seleção Natural como fim teleológico maximizador não tem aplicabilidade geral, mas sim é um caso restrito que exige, para ser alcançado, uma abstenção completa dos determinantes fundamentais que compõem uma abordagem genuinamente evolucionária e darwiniana.

Winter (1964) compreende que a empresa pode não estar verdadeiramente comprometida em obter lucros, muito menos máximos. Isto poderia suceder, uma vez que os gestores da firma estão livres para perseguir outros objetivos que não sejam a maximização dos lucros. ${ }^{18}$ Assim sendo, Winter defende que é necessário analisar as estruturas que compõem a firma como organização para compreender o seu comportamento efetivo.

A teoria neoclássica parte do pressuposto de que a firma maximiza, ou seja, a teoria ortodoxa incorpora como elemento metodológico um resultado previamente definido. Nesse sentido, Winter (1964), destaca que na visão neoclássica existe uma função bem definida para as hipóteses auxiliares que de alguma forma contradigam estas pré-concepções teóricas:

The auxiliary hypothesis which restricts the predictive range of the traditional theory to market phenomena is an ex post amendment to the theory; furthermore, it is not an amendment that suggests a new range of testability for the theory as amended, but one that rules out tests considered ex ante to be appropriate. (WINTER, 1964, p. 22).

Dessa forma, Winter (1964) retoma uma crítica levantada por Veblen (1898) que argumenta que o método dos economistas clássicos é o de construir leis que apontam para um fim pré-estabelecido como uma

17 O escopo do presente trabalho não busca analisar de forma detida a totalidade das críticas relativas à ideia de maximização como decorrência de um processo de seleção, mas sim verificar a inconsistência da abordagem de Friedman (1953) com relação aos desenvolvimentos das ideias das ciências evolucionárias. Desta forma recomendamos Winter (1964) e Hodgson (1994) para uma análise mais aprofundada a respeito das condições restritivas assinaladas neste trecho.

18 Galbraith $(1967 ; 1983 ; 2004)$ analisou detidamente o comportamento da firma e a relação entre os interesses da administração e dos proprietários, confirmando a possibilidade levantada por Winter (1964). Na realidade, há uma extensa literatura a respeito dos conflitos e das formas de alinhamento entre os interesses dos proprietários e acionistas da firma influenciada pelo trabalho seminal de Berle e Means (1932). Para uma interessante apreciação sobre o debate contemporâneo sobre essa questão, ver Lazonick e O'Sullivan (2000). 
tendência. Esta pré-concepção serve como parâmetro para a construção de teorias nas quais:

[...] the investigator contents himself with an appeal to its legitimation for premises that run back of the facts with which he is immediately, for the 'controlling principles' that are conceived intangibly to underlie the process discussed, and for the 'tendencies' that run beyond the situation as it lies before him. (VEBLEN, 1898, p. 382).

Assim sendo, observamos que Friedman (1953) realizou uma interessante transição da ideia da hipótese de maximização como um fundamento "animista" para um argumento teleológico, ou seja, Friedman (1953) passa de uma concepção sobre a natureza maximizadora das firmas análoga a uma "lei natural", fundada na ideia de "a God-given notation of the hedonistic calculus" (VEBLEN, 1909, p. 631), para a concepção de que o comportamento maximizador possui a chancela de um processo baseado na ideia de Seleção Natural. O argumento de Friedman (1953) é, portanto, teleológico e antievolucionário ao estabelecer um fim ou objetivo para o processo de Seleção Natural das firmas.

A preservação do princípio maximizador compromete a tentativa neoclássica de adequar uma ideia evolucionária darwiniana de Seleção Natural a um ideal de teoria profundamente essencialista. É importante reiterar a visão de que uma teoria evolucionária legítima não dá espaço para leis naturais em termos teleológicos. Nas palavras de Veblen (1898): "The notion of a legitimate trend in a course of events is an extra evolutionary preconception, and lies outside the scope of an inquiry into the causal sequence in any process" (VEBLEN, 1898, p. 182).

O trabalho de Winter (1964) é fundamental nesse sentido, pois identifica os equívocos teóricos da concepção de Seleção Natural da forma como foi empregada na perspectiva neoclássica. Neste contexto, Winter é claro em explicitar como a ideia sintetizada por Friedman (1953) é vaga e insuficiente para compreender os mecanismos de seleção e a natureza do processo evolucionário.

A bem da verdade, para que a seleção na óptica darwiniana aconteça é necessário que, em um tempo cronológico, existam elementos que variem e que sejam herdáveis. Isto não é contemplado em Alchian (1950), Enke (1951) ou Friedman (1953). No trabalho destes autores não há nenhum elemento que explique por que as firmas que maximizaram no passado voltariam a maximizar no futuro. Assim, mesmo havendo um processo de seleção que leva à sobrevivência das firmas maximizadoras, não há, na perspectiva desses autores, nada que teoricamente comprometa essas firmas a maximizar em períodos posteriores, ou seja, não se 
elabora nenhum elo histórico que ligue os eventos nestas abordagens. O termo "Seleção Natural" é relegado por esses autores a um "mecanismo de limpeza”, a imagem metafórica de uma vassoura, que elimina o não adaptado, desconsiderando a importância dos princípios de variação e herança como componentes de uma abordagem evolucionária. Compreendendo essas deficiências desta perspectiva "evolucionária" neoclássica, Dosi e Nelson (1994) assinalam de forma enfática que:

The "as... if" argument by Milton Friedman (1953) can be considered the most rudimentary use of an evolutionary point of view in order to justify the assumptions of equilibrium and rationality. (DOSI; NELSON, 1994, p. 154).

Nesse sentido, Hodgson (1994) é claro em destacar que "[...] for natural selection work there must be heritable variation in fitness and this is missing from Friedman's account" (HODGSON, 1994, p. 448). Assim, é útil salientar que a construção acerca da Seleção Natural nos moldes neoclássicos não levou em conta os avanços científicos da própria teoria darwiniana, pois o surgimento da analogia de Seleção Natural no mundo econômico iniciada por Alchian (1950) não contemplou os elementos ontológicos que governam a própria seleção natural no mundo biológico, sendo estes os princípios de variação, seleção e herança.

De maneira completamente oposta aos seus contemporâneos neoclássicos, Winter (1964) construiu uma teoria evolucionária específica muito mais consistente e apoiada nos próprios avanços da teoria sintética da Evolução. Nesse sentido, a distinção genótipo-fenótipo, inexistente no argumento neoclássico se apresenta como uma evidência da superioridade da visão evolucionária de Winter. Não é à toa que Hodgson (1994) entende que essa distinção importante no trabalho de Winter pode ser assinalada como a pedra fundamental para a construção do clássico Uma Teoria Evolucionária da Mudança Econômica, de Nelson e Winter (1982):

The genotype-phenotype distinction in biology suggests to Winter an analogous and important distinction in the socioeconomic sphere: between rules of action and action itself. Nelson and Winter (1982) develop the idea that habits or routines act as the economic analogue of gene in biology. (HODGSON, 1994, p. 416).

O tópico seguinte dedica-se a apresentar o modelo evolucionário básico de Winter (1964). Com efeito, o objetivo do tópico não é o de verificar todos os desenvolvimentos da ideia de Winter, mas sim compreender os conceitos gerais de sua abordagem evolucionária, eviden- 
ciado como esta formalização acaba incorporando as concepções que fundamentam uma verdadeira ciência evolucionária darwiniana se postando como uma alternativa consistente à interpretação neoclássica.

\section{O Modelo Geral de Winter (1964): Metodologicamente Evolucionário}

A abordagem inovadora de Winter (1964) assinala fundamentalmente que há de existir uma ligação entre os mecanismos decisórios e a estrutura da organização que, como vimos, é elemento não contemplado no argumento de Seleção Natural neoclássico. Nesse aspecto, o tratamento que Winter dispensa para entender o mundo econômico revela a necessidade de incorporar um conceito genético como componente ontológico para utilizar a ideia de Seleção Natural na Economia. Em Winter (1971), o autor é explícito: "To make a 'natural selection' argument plausible in economics, some mechanism playing the role of genetic inheritance must be discovered" (WINTER, 1971, p. 245).

Nesse mesmo sentido, Dobzhansky e Allen (1956) argumentam que para que a concepção de Seleção Natural seja absorvida por completo é preciso que as unidades de seleção sejam caracterizadas pela capacidade de sobrevivência diferencial decorrente de sua composição genética:

Para ser efetiva a seleção natural tem de ser seletiva. Em média, os sobreviventes devem ser melhor adaptados para viver do que os não sobreviventes. Os sobreviventes devem ser mais fortes, ou mais inteligentes [...] Mas nem mesmo todas essas virtudes combinadas melhorarão a qualidade da progênie a menos que a aptidão dos sobreviventes e a inaptidão dos extintos sejam devidas aos seus genes. (DOBZHANSKY; ALLEN, 1956, p.324-325, grifo nosso).

Da mesma maneira, Popper (1978), também reforça o papel da perspectiva genética como componente necessário para uma concepção de Seleção Natural completa: "[...] the selection pressures, if there are any, will leave their imprint upon the genetic material" (POPPER, 1978, p. 145). Analisando a visão evolucionária darwiniana de Winter (1964), Hodgson (1994) assinala a crítica fundamental ao conceito de Seleção Natural para a hipótese maximização nos termos da analogia gene-rotinas: "The key question is not 'will maximizing behaviour be selected?' but 'will routines giving rise to maximization become dominant through repeated selection?'” (HODGSON, 1994, p. 424). 
Dessa maneira, para além de conter as críticas mais contundentes ao argumento de Seleção Natural como justificativa para a maximização, Winter (1964) propõe uma profícua abordagem evolucionária alternativa, muito mais aderente à metodologia darwiniana. Nesse sentido, veremos a seguir como Winter constrói sua perspectiva, enfatizando o caráter dinâmico e não teleológico de sua proposta, contrastando fortemente com o argumento "evolucionário" para a maximização, cristalizado no trabalho de Friedman (1953).

O propósito do modelo de Winter (1964) é buscar compreender a dinâmica evolucionária decorrente da interação de um conjunto de firmas e sua relação com um ambiente específico. O comportamento das firmas não é convergente, e muito menos homogêneo. Cada ação tomada pela empresa deriva de sua própria observação e interpretação a respeito de um estado de mundo. Assim, cada firma determina uma ação específica, completamente dependente de sua forma organizacional. ${ }^{19}$ Como decorrência, Winter compreende que os resultados vão ser variáveis, sendo que as forças seletivas agem sobre as firmas utilizando estes resultados como parâmetros relevantes. Porém, ao contrário da perspectiva de Friedman (1953), os impactos da seleção são entendidos como distintos em cada firma. Desta forma, veremos que o processo evolucionário de Winter não possui o elemento teleológico da "convergência maximizadora" derivado do argumento neoclássico.

O modelo evolucionário de Winter (1964) utiliza um sistema de equações em diferenças, tendo como objetivo investigar de maneira formal o comportamento dinâmico da firma. É importante compreender que a utilização desse sistema de equações insere um componente dinâmico e temporal para determinação do comportamento da firma, ausente da abordagem neoclássica.

Winter (1964) inicia sua explicação definindo conjuntos, sub-conjuntos e equações. As letras maiúsculas $(A, X, W, F)$ representam os conjuntos, as minúsculas $(a, x, w, f)$ representam os elementos dos conjuntos. As funções são representadas por letras gregas $(\alpha, \eta, \varphi)$. O subescrito $j$ indica que aquele conjunto ou elemento do conjunto está associado com a firma $j$. O subescrito $t$ indica o estado possível de uma entidade no momento $t$.

A primeira definição necessária é a ideia de estado do mundo, o qual é composto pelas variáveis de estado das firmas conjuntamente com as variáveis externas. O estado do mundo é parcialmente descrito

19 A relação entre recursos e serviços esposada por Penrose (1959) permeia a concepção evolucionária de Winter (1964). Esta perspectiva abriu caminho para a concepção das rotinas como elementos análogos à relação genótipo-fenótipo da teoria sintética da Evolução, cristalizada no que Winter compreende aqui como a interação entre forma organizacional e a ação da firma. 
atendo-se ao estado das $m$ firmas que o compõem, isto é feito por um vetor de $p$ variáveis de estado da firma. Estas variáveis de estado podem ser: a planta, as máquinas, os dados de decisões tomadas no passado etc. O vetor de estado da firma pode ser descrito por $f_{\mathrm{jt}},(\mathrm{j}=1,2,3 \ldots \mathrm{m})$, o conjunto de possíveis vetores de estado da firma será $F_{j}$.

Para representar as variáveis externas às firmas, que retratarão condições externas, como o tempo, impostos, guerras, usamos o vetor $w_{t}$. Desta forma, um possível estado de mundo $x_{t}$ é representado pelo conjunto das variáveis de estado da firma $f_{j \mathrm{t}}$ das $m$ firmas em conjunto com o vetor das variáveis externas $w_{t}$. Desta forma um estado de mundo possivel $x_{t}$ poderia ser representado pelo vetor: $\mathrm{W}$

$$
x_{t}=\left(f_{1 t} f_{2 t} \ldots, f_{m t}, w_{t}\right)=\left(f_{j t}, w_{t}\right)
$$

O processo de decisão das firmas ocorre em dois estágios distintos. No primeiro estágio, uma firma j, no momento $t$, obtém uma informação $y_{j t}$ sobre o estado do mundo, onde $y_{j t}$ é um subconjunto das possíveis informações sobre estado do mundo que a firma $j$ poderia obter $\left(Y_{j}\right)$. A informação sobre o estado do mundo é uma função $\eta$ sobre o estado do mundo real $\left(x_{t}\right)$ no momento $t$. Desta forma teremos a seguinte função:

$$
y_{j t}=\eta_{j}\left(x_{t}\right)
$$
firma $j$.

Winter (1964) chama o parâmetro $\eta_{j}$ de estrutura informacional da

O segundo estágio do processo de decisão da firma é a escolha de uma ação $a_{j t}$ dentro de um conjunto de $A_{j}$ possíveis ações da firma j. A ação, porém, está limitada ao estado da firma $f_{j \mathrm{t}}$ e à informação sobre o estado do mundo que a firma possui $\left(y_{j t}\right)$. A regra de ação $\alpha_{j}$ determina qual é a ação que a firma deve tomar dependendo da informação sobre o estado do mundo e o estado da firma. Assim temos a seguinte equação:

$$
a_{\mathrm{jt}}=\alpha_{\mathrm{j}}\left(y_{\mathrm{jt}}, f_{\mathrm{jt}}\right)
$$

O par ordenado $\left(\alpha_{j}, \eta_{j}\right)$ é o que Winter (1964) chamou de forma organizacional da firma, que pode ser compreendido como o conjunto de regras que guiam o comportamento da empresa (rotinas), atuando tanto na captação de informação do mundo à sua volta $\left(\eta_{j}\right)$, quanto na ação através de seus recursos, sobre esse mundo $\left(\alpha_{\mathrm{j}}\right)$. O conjunto de regras gerais, ou forma organizacional da firma, é representado por $\varnothing_{j}$, assim: 


$$
\varnothing_{j}=\left(\alpha_{j}, \eta_{j}\right)
$$

Tendo isso definido, pode-se compreender de forma evolucionária a interação do comportamento das empresas com o ambiente. Uma equação em diferenças pode ser criada para compreender como um estado de mundo se transforma no decorrer do tempo. A determinação de $x_{t+1}$ é dada por uma função $\psi$ do estado do mundo no período anterior $x_{t}$, as ações do conjunto das $m$ empresas no período anterior $a_{t}$ e o próprio período $t$, que Winter justifica como uma mudança da própria função, $\psi$ devido a alterações temporais como descritas no seguinte trecho:

Time appears as an argument of the function $\psi$ because it is interesting in some specific models, to examine the implications of changes through time in such things as consumer preferences and the actions of government. (WINTER, 1964, p. 247).

Assim temos a seguinte equação em diferenças em primeira ordem:

$$
x_{t+1}=\psi\left(x_{t}, a_{t}, t\right)
$$

O seguinte sistema de equações em diferenças simultâneas destaca que, uma vez que um estado do mundo inicial seja especificado $\left(x_{0}\right)$, pode-se determinar a mudança nos estados do mundo e nos estados da firma como segue:

$$
\begin{aligned}
& x_{t+1}=\psi_{w}\left(w_{t}, a_{t}, t\right) \\
& f_{t+1}=\psi_{f}\left(x_{t}, a_{t}, t\right)
\end{aligned}
$$

Visando a inserir o processo de Seleção Natural nesta construção, Winter (1964) sustenta que existiria um conjunto de vetores variáveis de estados possíveis $D_{j}$ contendo todos os vetores que caracterizariam que a firma $j$ estaria eliminada do mercado. Assim, se tivermos a função $\psi_{f}$ que implique um $f_{j t+1} \in D_{j}$, saberemos que a firma encerrará suas ativi-

dades permanentemente. Teríamos ainda que todas as formas organizacionais da firma $j\left(\varnothing_{j}\right)$, possuem a propriedade de que quando $f_{j t} \in D_{j}$ teremos um $\alpha_{j}\left(y_{j t}, f_{j t}\right)=\overline{a_{j}}$, sendo que $\overline{a_{j}}$ é identificado como uma não ação da firma j.

No modelo de Winter (1964), encontramos uma abordagem muito mais completa do que o argumento de Seleção Natural neoclássico. A 
concepção de racionalidade limitada que Alchian (1950) assinalou, é o fundamento da equação (2), em que a informação sobre um estado de mundo de uma firma $\left(y_{j t}\right)$ não é completa, ou seja, ela depende de como a firma compreende o estado de mundo $\left(x_{t}\right)$, o que se dá através de sua estrutura informacional $\left(\eta_{\mathrm{j}}\right)$.

A ação depende dessa informação sobre o estado de mundo e o estado da firma. Assim sendo, na equação (3) temos a ligação entre os recursos da firma $\left(y_{j t}, f_{j t}\right)$ e serviços $\left(a_{j t}\right)$, determinados pelas rotinas, ou regras de ação $\left(\alpha_{j t}\right)$.

A concepção de forma organizacional da firma, apesar de não ser explícita no trabalho de Winter (1964), é análoga à função dos genes na teoria sintética da Evolução. Tal semelhança é dada pela característica comum de tanto as rotinas como os genes serem regras que levam à ação. ${ }^{20}$ Da mesma maneira, Dawkins (1976) explicita a função dos genes como regras que determinam o comportamento:

Os genes controlam o comportamento das suas máquinas de sobrevivência, não diretamente, com seus dedos nas cordas das marionetes, mas indiretamente, como um programador de computador. (DAWKINS, 1976, p. 117).

Vemos que $D_{j}$ é firma específico. Compreende um conjunto de vetores possíveis de variáveis de estado da firma $j$, assim sendo, atribuímos a $D_{j}$ a propriedade de seletor das firmas. A cada variação de $t, f_{\text {it }}$ se altera (segundo a equação 6), evidenciando a dinâmica temporal do processo de seleção. É importante frisar que cada firma possui um conjunto $D$ distinto, isso significa que a seleção atua de forma diferente em cada empresa, não havendo nenhum horizonte teleológico para este processo evolucionário, ao contrário do que ocorre quando recorremos ao argumento de Seleção Natural neoclássico e seu fim maximizador. ${ }^{21}$

20 Recomendamos a leitura de Nelson e Winter (1982), no qual relação entre regras de ação e comportamento é apresentada com maior profundidade, assim como a comparação entre a função dos genes, os hábitos individuais e as rotinas.

21 Vale assinalar neste ponto, que verificamos a existência de uma lacuna explicativa no trabalho de Winter (1964) no que concerne à sua concepção do conjunto de vetores de estados $D_{i}$. Apesar do conjunto firma específico $D_{j}$ determinar os estados de firma $j$ que indicam que ela estaria eliminada do mercado, retirando qualquer interpretação teleológica de sua abordagem, Winter (1964) não explica o processo que determina os valores que conformam o conjunto $D_{j}$. Nesse sentido, se quisermos compreender $D_{j}$ através dos elementos de uma abordagem evolucionária darwiniana, deveríamos especificá-lo como dependente das variáveis de estado de mundo $x_{t}$ dada pela equação (1). Isto porque, somente através da especificação da dependência de $D_{j}$ aos valores de $x_{t}$, evidenciar-se-ia que o ambiente seletivo é comportado pelas próprias entidades selecionáveis em conjunto com variáveis externas, ou seja, $\left(f_{\mathrm{i}}, w_{\mathrm{t}}\right)$. Como vimos no tópico anterior, esta concepção específica de $D_{i}$, como dependente das relações que ocorrem dentro da dinâmica ambiental, está totalmente de acordo com a perspectiva darwiniana. 
Fica claro, portanto, que a abordagem acerca dos mecanismos de atuação da Seleção Natural de Winter (1964) revela uma maior conformidade com concepções evolucionárias darwinianas do que a abordagem neoclássica da Seleção Natural. A ideia de Evolução visando a estados pré-concebidos ótimos, que permeia a abordagem de Friedman (1953), não faz parte do modelo de Winter e é fortemente refutada por qualquer teoria evolucionária de fundo darwiniano. A partir da perspectiva da teoria sintética da Evolução, Dobzhansky e Allen (1956) reafirmam este fundamento darwiniano, explicitando que a evolução através de um processo de Seleção Natural não admite nenhum estado futuro pré-concebido ou teleologia. ${ }^{22}$

A seleção natural é, então, acarretada pela sobrevivência dos geneticamente aptos, não dos geneticamente mais aptos. A 'sobrevivência dos mais aptos', de Spencer, era um slogan de valor na batalha em prol da teoria da evolução. Mas o superlativo retórico falseia a situação real pelo fato de exagerar a ferocidade da luta pela existência. (DOBZHANSKY; ALLEN, 1956, p. 325, grifo nosso).

O próprio Darwin (1859) já deixava claro que a Seleção Natural não produz resultados ótimos. Nesse sentido, o autor já trazia o exemplo do olho humano, que, apesar de toda a sua complexidade, deve ser corrigido através do uso de lentes. Para Darwin, as vespas ou abelhas também evidenciavam que a imperfeição pode ser uma resultante da Seleção Natural:

Acaso deveríamos considerar perfeitos os ferrões das vespas ou das abelhas, sabendo que esses, quando usados para atacar inimigos desses insetos, não podem ser retirados, uma vez que são serrilhados para dentro, e que por isso seu possuidor fatalmente morrerá, visto que a perda do ferrão acarretará também a perda de suas vísceras? (DARWIN, 1859, p. 267).

Usando um conjunto de evidências que refutam a ideia da Seleção Natural, levar a arranjos ótimos, Darwin (1859) conclui que: "A Seleção

22 Nesse sentido vale citar uma importante pesquisa realizada pela Universidade de Cornell através do "Cornell Evolution Project" (www.cornellevolutionproject.org), comandado pelo zoólogo norte-americano Gregory Graffin. Nesta pesquisa foi elaborado um questionário em que se abordam diversos temas como a ideia de evolução, religião e finalidade, respondido pelos 274 maiores cientistas evolucionistas vivos. A pesquisa é reveladora ao explicitar a não aceitação por parte destes cientistas da ideia de propósito final na perspectiva evolucionária. Desta forma, quando perguntado: "Qual é a sua visão de propósito e progresso na evolução?", $41,61 \%$ dos cientistas disseram não ver nem propósito nem progresso na evolução, $48,30 \%$ disseram ver progresso, porém não propósito, 4,7\% disseram ver progresso e propósito, 1,34\% disseram ver propósito mas não progresso e 4,03\% deixaram de responder a essa pergunta. 
Natural não terá de produzir necessariamente a perfeição absoluta, e esta, tanto quanto nos permite julgar nosso limitado conhecimento, não deverá ser encontrada em parte alguma deste mundo" (DARWIN, 1859, p. 271).

Fica claro, portanto, que, para além de uma repercussão retórica, como no caso do argumento de seleção neoclássico, os avanços da biologia evolucionária afetaram de forma contundente a perspectiva econômica de Winter (1964). Com o mesmo espírito evolucionário exaltado pelo chamado vebleniano, Winter conseguiu fundar sua abordagem na dinâmica dos princípios darwinianos, assimilando uma perspectiva causal e cumulativa associada aos elementos de variação, herança e seleção. Desta forma, o autor pôde desenvolver, a partir do debate gerado pela controvérsia marginalista, uma teoria evolucionária muito mais apropriada e consistente para compreender o comportamento da firma do que aquela fundada no ideal essencialista neoclássico.

\section{Considerações Finais}

Este artigo partiu da constatação de que apesar do atual fenômeno de disseminação da utilização do termo "economia evolucionária", existe um recorrente esvaziamento de sentido associado ao que essa denominação representa.

Nesse sentido, o trabalho identifica o debate acerca da maximização de lucros da firma, dentro do que ficou conhecido como controvérsia marginalista, como um dos importantes momentos da gênese desta atual divergência a respeito do significado que a ideia de pensamento evolucionário possui na economia.

Porém, para compreender os desenvolvimentos "evolucionários" levados a cabo neste período específico das ideias econômicas, é inevitável utilizar um ferramental analítico cientificamente reconhecido como evolucionário. Desta maneira, a apresentação dos princípios construídos pela biologia evolucionária em meados do século XX, sob o rótulo de "teoria sintética da Evolução", teve uma importância dupla neste trabalho. Primeiro, porque ao realizarmos este esforço de revisão, procuramos especificar de forma clara, os elementos científicos que constituem a última fronteira do pensamento evolucionário. Segundo porque esta apresentação inicial ajuda-nos a caracterizar o próprio momento histórico em que a construção do argumento de Seleção Natural na economia, iniciada por Alchian (1950), estava inserida.

Dessa forma pudemos compreender como, a partir da ideia de Alchian (1950) e Enke (1951), surgiram duas abordagens "evolucionárias" distintas. Uma perspectiva, defendida de maneira pioneira por 
Friedman (1953), absorvia um argumento selecionista como justificativa para a hipótese de maximização. De forma totalmente oposta a esta caracterização de processo evolucionário, Winter (1964) apresenta outra abordagem, que fornece ao economista uma alternativa factível à perspectiva neoclássica, consubstanciada aqui na apresentação de seu modelo evolucionário geral.

A partir de sua visão caracterizadamente darwiniana, Winter (1964) recoloca de forma adequada a ideia de Seleção Natural para compreender o comportamento da firma. Diferentemente de Friedman (1953), Winter não entende a Seleção Natural como uma "vassoura teleológica" que elimina as variações e comanda um processo em direção à "perfeição" (maximização), mas sim a entende como um movimento interativo sem um fim pré-concebido. Ademais, essa compreensão evolucionária de Winter, além de consistente com as ideias fundadoras de Darwin (1859), é aderente à forma de pensamento compartilhado e estabelecido pela maioria esmagadora dos grandes expoentes da biologia evolucionária contemporânea. Desta maneira, explicitamos que metodologia evolucionária darwiniana, quando aplicada de forma apropriada, pode levar a resultados muito mais consistentes com a complexidade do mundo socioeconômico do que os argumentos neoclássicos, característicos do que Veblen (1898) denominou de "economia taxonômica".

Finalmente, gostaríamos de apontar para a necessidade de um aprofundamento dessa temática que, a nosso juízo, pode lançar luzes sobre os caminhos mais férteis a serem trilhados na busca de uma abordagem verdadeiramente evolucionária nas ciências econômicas, possibilitandonos ultrapassar o marco das mecânicas elegantes e estáticas que ainda delimita as fronteiras de boa parte da teoria econômica contemporânea.

\section{Referências}

ALCHIAN, A. A. Uncertainty, evolution, and economic theory. Journal of Political Economy, v. 58, n. 3, p. 211-221, 1950.

ANDERSON, E. Strategic implications of Darwinian economics for selling efficiency and choice of integrated or independent sales forces. Management Science, v. 34, n. 5, p. 599-618, May, 1988.

BERLE, A.; MEANS, G. The modern corporation and private property. New York: Harcourt, Brace E World, 1932.

BLUME, L.; EASLEY, D. Market competition and selection. In: DURLAUF, S.; BLUME, L. The New Palgrave Dictionary of Economics. Palgrave Macmillan, 2007.

CARTER, G. S. A teoria da evolução e a evolução do homem. In: MUSSOLINI. G. (Org.). Evolução Raça e Cultura. São Paulo: Editora Nacional, 1953. 
CHAMBERLIN, E. H. The theory of monopolistic competition. Harvard University Press, 1933.

CORDES, C. Darwinism in economics: from analogy to continuity. Journal of Evolutionary Economics, v. 16, n. 5, p. 529-541, 2006.

DARWIN, C. A origem das espécies. São Paulo: Martin Claret, 1859.

DAWKINS, R. O gene egoísta. São Paulo: Companhia das Letras, 1976. . O relojoeiro cego. São Paulo: Companhia das Letras, 1986.

. Universal Darwinism. In: BENDALL. (Org.). Evolution from Molecules to Man. Cambridge: Cambridge University Press, 1983.

DOBZHANSKY, T.; ALLEN, G. A seleção natural na humanidade moderna. In: MUSSOLINI.G. (Org.). Evolução Raça e Cultura. São Paulo: Editora Nacional, 1956.

DOBZHANSKY, T. Genetics and the origin of species. New York: Columbia University Press, 1937.

DOSI, G.; NELSON, R. An introduction to evolutionary theories in economics. Journal of Evolutionary Economics, v. 4, n. 3, p. 153-172, 1994.

ENKE, S. On maximizing profits: A distinction between Chamberlin and Robinson. The American Economic Review, v. 41, n. 4, p. 566-578, sep. 1951.

FRIEDMAN, M. Essays in positive economics. Chicago: The University of Chicago Press, 1953.

GALBRAITH, J. K. A economia das fraudes inocentes: verdades para o nosso tempo. São Paulo: Companhia das Letras, 2004.

. O Novo Estado Industrial. São Paulo: Nova Cultural, 1967.

. Anatomia do poder. São Paulo: Livraria Pioneira Editora, 1983.

GOULD, S. J. Introduction. In: DOBZHANSKY, T. Genetics and the origin of species. New York: Columbia University Press, 1982.

HIRSHLEIFER, J. Economics from a biological viewpoint. Journal of Law and Economics, v. 20, n. 1, p. 1-52, apr. 1977.

HODGSON, G. A response to Christian Cordes and Clifford Poirot. Journal of Economic Issues, v. 41, n. 1, p. 265 -276, mar. 2007.

. Darwinism in economics: from analogy to ontology. Journal of Evolutionary Economics, v. 12, n. 3, p. 259-281, 2002.

. Darwinism, causality and the social sciences. Journal of Economic Methodology, v. 11, n. 2, p. 175-194, jun. 2004.

How can evolutionary economics evolve? In: ARUKA, Y. Evolutionary Contro-

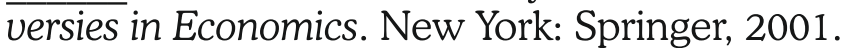

. Introduction. In: HODGSON, G. M. The Foundations of Evolutionary Economics: 1890-1973. Cheltenham: Edward Elgar, 1998.

. Optimisation and evolution: Winter's critique of Friedman revisited. Cambridge Journal of Economics, v. 18, n. 4, p. 413-430, 1994. 
HODGSON, G. M.; KNUDSEN, T. Why we need a generalized darwinism and why a generalized darwinism is not enought. Journal of Economic Behavior, v. 61, n. 1, p. 1-19, sep. 2006.

HUXLEY, J. O processo evolutivo. In: MUSSOLINI, G. (Org.). Evolução, raça e cultura. São Paulo: Editora Nacional, 1954.

JABLONKA, E; LAMB, M. J. Evolution in four dimensions. Cambridge: The Massachusetts Institute of Technology Press, 2005.

KLAMER, A.; LEONARD, T. So what's an economic metaphor. In: MIROWSKY, P. Natural images in economic thought. New York: Cambridge University Press, 1994.

LAZONICK, W.; O'SULLIVAN, M. Maximizing shareholder value: a new ideology for corporate governance. Economy and Society, v. 29, n. 1, p. 13-35, 2000.

LEATHERDALE, H. The role of analogy, model and metaphor in science. Amsterdam: North-Holland Publishing Company, 1974.

LEWOTIN, R. C. The genetic basis of evolutionary change. New York: Columbia University Press, 1974.

LUZ, M. R. S.; FRACALANZA, P. S. Darwinismo universal e economia evolucionária: elementos para um debate. In: ENCONTRO NACIONAL DE ECONOMIA POLÍTICA, 13, 2008, João Pessoa. Anais..., Diamantina, p. 1-16, 2008.

MACHLUP, F. Marginal analysis and empirical research. The American Economic Review, v. 36, n. 4, p. 519-554, 1946.

MAYR, E. Uma ampla discussão: Charles Darwin e a Gênese do Moderno. Pensamento Evolucionista. Ribeirão Preto: FUNPEC Editora, 2006.

McCLOSKEY, D. The rhetoric of economics. Madison: University of Winsconsin Press, 1985.

MONGIN, P. The marginalist controversy. In: DAVIS, J.; HANDS, W.; MAKI, U. (Org.). Handbook of Economic Methodology. London: Edward Elgar, p. 558-562, 1997.

NELSON, R.; WINTER, S. Uma teoria evolucionária da mudança econômica. Campinas: Editora Unicamp, 1982.

PENROSE, E. A teoria do crescimento da firma. Campinas: Editora Unicamp, 1959.

Biological analogies in the theory of the firm. The American Economic Review, v. 42, n. 5, p. 804-819, Dec., 1952.

POPPER, K. Natural selection and the emergence of mind. In: RADNITZKY, G. Evolutionary epistemology, rationality, and the sociology of knowledge. La Salle: Open Court, 1978.

POSSAS, M. L. Economia evolucionária neo-schumpeteriana: elementos para uma integração micro-macrodinâmica. Estudos Avançados, v. 22, n. 63, p. 281-305, 2008.

SCREPANTI, E.; ZAMAGNI, S. Panorama de Historia del pensamiento económico. Barcelona: Editorial Ariel, 1997.

SIMPSON, G. G. The problem of plan and purpose in nature. The Scientific Monthly, v. 64, n. 6, p. 481-495, 1947.

VEBLEN, T. The limitations of marginal utility. The Journal of Political Economy, v. 17, n. 9, p. 620-636, 1909. 
. The preconceptions of economic science. The Quarterly Journal of Economics, v. 14, n. 2, p. 240-269, 1900.

. Why is economics not an evolutionary science? The Quarterly Journal of Economics, v. 12, n. 4, p. 373-397, 1898.

WINTER, S. Economic "natural" selection and the theory of the firm. In: HODGSON, G. M. (Org.). The Foundations of Evolutionary Economics: 1890-1973. Cheltenham: Edward Elgar, 1964.

Satisficing, selection, and the innovating remnant. The Quarterly Journal of Economics, v. 85, n. 2, p. 237-261, 1971.

WITT, U. What is specific about evolutionary economics? Journal of Evolutionary Economics, v. 18, n. 5, p. 547-575, 2008.

Recebido: 26/06/2010.

Aceito: 10/08/2010. 